it was not due to the liniment of camphor; hence we suggested the substitution of oil of betula for the methyl salicylate and our troubles were at any end. If you wish to use methyl salicylate in combination with iodine would suggest that it be tested first for its iodine absorption value, so as to avoid possible subsequent controversies and explanations.

Home-made Dusting Boxes.-Occasionally we are called upon to dispense small quantities of medicinal agents in a sifting-top box, and as it is desired to concentrate the siftings upon a small space upon the body, we have found it expedient to manufacture the sifting-top boxes extemporaneously by punching the necessary holes in a round utility box with an aw of small size, holding against the under side of the lid a section of a broom handle sawed off at right angles. By placing the label upon the box so as to cover the junction point of the top and of the body of the box (a shouldered one only should be used) there is no danger of the lid being shaken off, with its unpleasant results.

\title{
ONE CAUSE OF INSTABILITY IN COMPOUND SYRUP OF THE PHOSPHATES, N. F.
}

SAMUEL T. HENSEL, PH. G., DENVER, COLO.

When the method of procedure of the National Formulary is rigidly followed in the preparation of this syrup, the product will after a short time become cloudy, finally throwing down a precipitate-the time required varying with the order in which the ingredients are added in making the initial solution of calcium carbonate.

By referring to the N. F. formula it will be observed:

First. That the amount of glycerin employed is very great compared with the aqueous solvent.

Second. In the preparation of the initial solution containing the calcium carbonate, glycerin is the first in the order named, followed by the addition of a comparatively small amount of orange flower water.

If the glycerin is first added to the calciun carbonate, citric acid, potassium bicarbonate, sodium bicarbonate, etc., solution is extremely slow, the mass in the meantime swelling up to an enormous volume. carbon dioxide being expeller very slowly, and owing to the viscosity of the liquid a large percentage of the gas is held in suspension.

If, on the other hand, the orange flower water be first added to the calcium carbonate, citric acid, etc.. solution is effected very rapidly, a large portion of the carbon dioxide being expelled at once.

In either case, however. whether we add the glycerin or the orange flower water first, the result will finally be the same, there will be a precipitation of the calcium salt.

Third. By further inspection of the formula, we note that the amount of hot water (8 fluidounces) directed for the solution of the ferric phosphate and ammonium phosphate, is very largely in excess of the amount necessary to dissolve these two very soluble salts. Three fluidounces of hot water would be 
sufficient for the solution of these two salts, the other five fluidounces becoming available in effecting the solution of the calcium carbonate, etc.

For a long time $I$ have been confirmed in the belief that the deposit found in this syrup was chiefly calcium carbonate, and that it was to the large amount of carbon dioxide held in suspension by the viscosity of the liquid to which the precipitation is due.

When the glycerin and the orange flower water are added, the viscosity of the resulting mixture is such as to retard the complete elimination of the carbon dioxide set free, and since the coefficient of solubility of carbonic acid is a constant for a given temperature, a definite amount of the acid will be held in solution in its most chemically active state, i. e., in the form of $\mathrm{H}_{2} \mathrm{CO}_{2}$.

According to Mendeleeff, the coefficient of solubility of carbonic acid, that is to say, the number of grams by weight saturating 100 grams of water, is for the three different temperatures here given, as follows:

$\begin{array}{ccc}0^{\circ} \mathrm{C} . & 20^{\circ} \mathrm{C} . & 100^{\circ} \mathrm{C} . \\ 35 & 18 & \cdots\end{array}$

In other words, at $100^{\circ} \mathrm{C}$. carbon dioxide ceases to exist in aqueous solution.

Now, carbonic acid, although a weaker acid than either the citric or phosphoric acids, possesses a strong affinity for calcium and is capable of completely overcoming the excess of the two named acids, hence its tendency is to combine with the calcium to form calcium carbonate.

A short time ago, I made a tentative examination of a deposit found in a syrup which had been prepared for some time.

On first examination, the deposit proved insoluble in both hot and cold water.

I then treated it with diluted hydrochloric acid; solution was immediately effected, accompanied by brisk effervescence, indicating the presence of a carbonate.

I then determined to try my idea of modifying the method of procedure in the preparation of the initial solution of the calcium carbonate by utilizing the five fluidounces of surplus water referred to above, and bringing the mixture to a temperature of $212^{\circ} \mathrm{F}$., so as to completely eliminate the last vestige of the liberated carbon dioxide.

The calcium carbonate, citric acid, potassium bicarbonate, sodium bicarbonate, were introduced into a porcelain capsule, five fluidounces of distilled water were added and the mixture brought to the temperature of $212^{\circ} \mathrm{F}$., and the glycerin, orange flower water and tincture of cudbear, were then added in the order named. The temperature of $212^{\circ} \mathrm{F}$. should not be exceeded, nor prolonged beyond the time necessary for solution, or calcium citrate will be precipitated.

Solution of the ferric phosphate and ammonium phosphate was then accomplished by means of the remaining three fluidounces of hot water, this solution added to the initial solution and the resulting mixture filtered, the sugar added, and the whole agitated until solution was effected, in the manner directed in the National Formulary.

The result was a stable syrup, showing no sign of change after a month's storage under ordinary conditions. 